\title{
Theoretical characterization of molecular complexes formed between triplet vinyl nitrene and Lewis acids
}

\section{Darío J. R. Duarte, Margarida S. Miranda \& Joaquim C. G. Esteves da Silva}

\section{Structural Chemistry}

Computational and Experimental Studies of Chemical and Biological Systems

ISSN 1040-0400

Volume 26

Number 2

Struct Chem (2015) 26:565-571

DOI 10.1007/s11224-014-0519-y $\begin{array}{lr}\text { VOLUME 26, NUMBER } 2 & \text { April } 2015 \\ & 26(2) 365-638(2015)\end{array}$

ISSN 1040-0400
Computational and Experimental Studies of Chemical and Biological Systems

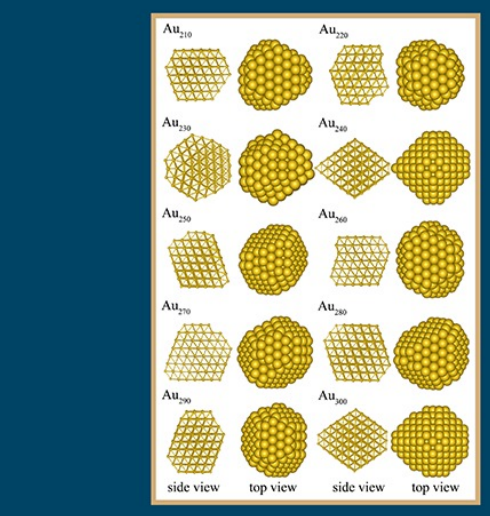

Springer 
Your article is protected by copyright and all rights are held exclusively by Springer Science +Business Media New York. This e-offprint is for personal use only and shall not be selfarchived in electronic repositories. If you wish to self-archive your article, please use the accepted manuscript version for posting on your own website. You may further deposit the accepted manuscript version in any repository, provided it is only made publicly available 12 months after official publication or later and provided acknowledgement is given to the original source of publication and a link is inserted to the published article on Springer's website. The link must be accompanied by the following text: "The final publication is available at link.springer.com". 


\title{
Theoretical characterization of molecular complexes formed between triplet vinyl nitrene and Lewis acids
}

\author{
Darío J. R. Duarte $\cdot$ Margarida S. Miranda • \\ Joaquim C. G. Esteves da Silva
}

Received: 16 July 2014/Accepted: 22 September 2014/Published online: 5 October 2014

(C) Springer Science+Business Media New York 2014

\begin{abstract}
In the current work, the complexes formed between triplet vinyl nitrene $\left({ }^{3} \mathrm{CH}_{2} \mathrm{CHN}\right)$ and some Lewis acids YA ( $\mathrm{LiH}, \mathrm{LiF}, \mathrm{BeH}_{2}, \mathrm{BeF}_{2}, \mathrm{BH}_{3}, \mathrm{BF}_{3}, \mathrm{ClH}, \mathrm{ClF}$, $\mathrm{HCl}, \mathrm{HF}$ ) have been investigated through calculations of the electronic structure. These calculations have been carried out in order to determine the energetic stability of the $\mathrm{N} \cdots \mathrm{Y}$ (with $\mathrm{Y}=\mathrm{Li}, \mathrm{Be}, \mathrm{B}, \mathrm{Cl}, \mathrm{H}$ ) interactions and also to understand their chemical nature. Quantum chemical calculations predict that the molecular complexes ${ }^{3} \mathrm{CH}_{2} \mathrm{CHN} \cdots \mathrm{Y}-\mathrm{A}$ are always more stable than the separated ${ }^{3} \mathrm{CH}_{2} \mathrm{CHN}$ and $\mathrm{Y}-\mathrm{A}$ species. The interaction energies range from $-0.98 \mathrm{kcal} \mathrm{mol}^{-1}$ (in $\mathrm{CH}_{2}=\mathrm{CHN} \cdots \mathrm{ClH}$ ) to $-39.03 \mathrm{kcal} \mathrm{mol}^{-1}$ (in $\mathrm{CH}_{2}=\mathrm{CHN} \cdots \mathrm{BH}_{3}$ ) at the $\mathrm{CCSD}(\mathrm{T}) /$ $6-311++\mathrm{G}(2 \mathrm{~d}, 2 \mathrm{p})$ level of theory. Accordingly, some of these complexes may serve to experimentally detect and characterize the elusive triplet vinyl nitrene species. Moreover, AIM theory, in particular the $L(\mathbf{r})=-1 / 4 \nabla^{2} \rho(\mathbf{r})$ function, reveals that the $\mathrm{N} \cdots \mathrm{Y}$ interactions established between the electron lone pair of the nitrogen atom and the charge density depletion region of the $\mathrm{Y}$ atom are mainly of electrostatic character.
\end{abstract}

Electronic supplementary material The online version of this article (doi:10.1007/s11224-014-0519-y) contains supplementary material, which is available to authorized users.

\section{J. R. Duarte}

Laboratorio de Estructura Molecular y Propiedades, Área de Química Física-Departamento de Química, Facultad de Ciencias Exactas y Naturales y Agrimensura, Universidad Nacional del Nordeste, Avenida Libertad 5460, 3400 Corrientes, Argentina

M. S. Miranda $(\bowtie)$ · J. C. G. E. da Silva Centro de Investigação em Química, Departamento de Química e Bioquímica, Faculdade de Ciências, Universidade do Porto, Rua do Campo Alegre, s/n, 4169-007 Porto, Portugal

e-mail: msmirand@fc.up.pt
Keywords Vinyl nitrene - Lewis acid - Charge density · QTAIM · Laplacian · VSCC

\section{Introduction}

Molecular interactions represent an important class of intermolecular forces in chemistry, biology, and materials science and play important roles in molecular recognition [1-4]. The hydrogen bond (HB) has been the subject of many studies and its key role in different reactions and phenomena is very well known [5-8]. At present other noncovalent interactions are also being extensively analyzed. These are, for example, the halogen bond (XB) $[9$, $10]$, the chalcogen bond $(\mathrm{ChB})[11,12]$, the beryllium bond (BeB) $[13,14]$, the boron bond (BB) $[15,16]$, and the lithium bond (LiB) [17, 18]. According to Grabowski [5], the term "Lewis acid-Lewis base interaction" seems to be more proper than the term "noncovalent interaction" for the $\mathrm{HB}, \mathrm{XB}$, and all other interactions where the complex formation is connected with significant electron charge redistribution. In all these Lewis acid-Lewis base interactions, the electrostatic forces are very important since the positively charged Lewis acid center interacts with the negatively charged Lewis base center. This is in line with the $\sigma$-hole concept which was applied to the XB and to other noncovalent interactions $[19,20]$.

On the other hand, in the decomposition reactions of organic azides it is commonly believed [21-25] that photolysis and thermolysis of these molecules leads, in a first stage, to the release of molecular nitrogen and to the formation of a nitrene. Nitrenes are typically very reactive and short-lived intermediates thus making their experimental detection and characterization a very difficult task. In a previous work on the decomposition mechanism of vinyl 
azide [26], we found that triplet vinyl nitrene $\left({ }^{3} \mathrm{CH}_{2} \mathrm{CHN}\right)$ is a minimum on the potential energy surface with one electron lone pair on the nitrogen atom centered along the $\mathrm{C}-\mathrm{N}$ bond axis. Thus, this lone pair can act as a Lewis base that interacts electrostatically with a Lewis acid to form a Lewis adduct. These adducts are probably stable species and their study would be of great importance to experimentalists who seek to detect and isolate nitrenes.

Recently van der Waals complexes have been studied through the matrix isolation technique. For example, Romano et al. have trapped in an argon matrix complexes formed between $\mathrm{CS}_{2}$ and dihalogen molecules $\mathrm{XY}$, where $\mathrm{XY}=\mathrm{Cl}_{2}, \mathrm{Br}_{2}, \mathrm{BrCl}, \mathrm{ICl}$, or IBr [27], and also $\mathrm{HCl}$ [28] and determined their IR spectra. Buchberger et al. [29] measured several IR bands of $\mathrm{FCH}_{2} \mathrm{CN} \cdots \mathrm{BF}_{3}$ and $\mathrm{ClCH}_{2}$ $\mathrm{CN} \cdots \mathrm{BF}_{3}$ complexes in solid nitrogen, argon, and neon. To the best of our knowledge, there are no examples in the literature where triplet vinyl nitrene has been detected and characterized experimentally. Therefore, we wonder if this technique could be used to detect the experimentally difficult to find triplet vinyl nitrene.

In this paper, we report a theoretical study of $1: 1$ molecular complexes involving triplet vinyl nitrene and some Lewis acids YA ( $\mathrm{LiH}, \mathrm{LiF}, \mathrm{BeH}_{2}, \mathrm{BeF}_{2}, \mathrm{BH}_{3}, \mathrm{BF}_{3}$, $\mathrm{ClH}, \mathrm{ClF}, \mathrm{HCl}, \mathrm{HF}$ ). The theoretical study of these systems may help experimentalists in the isolation of triplet vinyl nitrene.

\section{Computational details}

The geometries of all monomers (triplet vinyl nitrene and Lewis acids) and complexes were optimized, without any constraint, using the second order Møller-Plesset perturbation (MP2) [30] method with the $6-311++\mathrm{G}(2 \mathrm{~d}, 2 \mathrm{p})$ basis set. Frequency calculations at this computational level have been performed to confirm that the structures obtained correspond to minima. The electronic energy has been refined by means of single-point energy calculations at the $\operatorname{CCSD}(\mathrm{T})$ [31] level (CCSD augmented with a noniterative treatment of triple excitations) with the $6-311++\mathrm{G}(2 \mathrm{~d}, 2 \mathrm{p})$ basis set. The interaction energies have been calculated as the difference between the total energy of the complexes minus the sum of the energies of the isolated monomers. The basis set superposition error (BSSE) was taken into account using the counterpoise method proposed by Boys and Bernardi [32].

The calculations of local topological properties of the electron charge density at a critical point, as well as, the display of the molecular graphs were performed with the AIMAll [33] software, with the wave functions obtained at the MP2/6-311++G(2d,2p) level. All calculations of electronic structure were carried out using the Gaussian 03 suite of programs [34].

\section{Results and discussion}

In the current work, the complexes formed between triplet vinyl nitrene $\left({ }^{3} \mathrm{CH}_{2} \mathrm{CHN}\right)$ and some Lewis acids $\mathrm{YA}(\mathrm{LiH}$, $\mathrm{LiF}, \mathrm{BeH}_{2}, \mathrm{BeF}_{2}, \mathrm{BH}_{3}, \mathrm{BF}_{3}, \mathrm{ClH}, \mathrm{ClF}, \mathrm{HCl}, \mathrm{HF}$ ) have been investigated.

\section{Geometries of the complexes}

Optimized geometries and selected geometrical parameters of the complexes under consideration, obtained at the MP2/ $6-311++G(2 d, 2 p)$ level of theory, are shown in Fig. 1. It can be observed in this figure that the interatomic distances between the nitrogen atom and the acidic site $\mathrm{Y}(\mathrm{Li}, \mathrm{Be}, \mathrm{B}$, $\mathrm{Cl}, \mathrm{H}$ ) of the Lewis acids are relatively short, from 1.688 to $3.300 \AA$. The distances $d(\mathrm{~N} \cdots \mathrm{Y})$ are in agreement with the proposed range for the $\mathrm{LiB}$ [18], $\mathrm{BeB}[13], \mathrm{BB}[15,16]$, $\mathrm{XB}[35,36]$, and HB [7], respectively. The short $\mathrm{N} \cdots \mathrm{Y}$ is indicative of the existence of a significant interaction between the two monomers forming the complex and is result of the mutual penetration of $\mathrm{N}$ and $\mathrm{Y}$ atoms electronic densities. An interesting aspect of the results presented in Fig. 1 is the fact that the presence of the electronwithdrawing fluorine atom leads to an increase of the binding distance in the $\mathrm{LiB}, \mathrm{BeB}$, and $\mathrm{BB}$, while in the $\mathrm{XB}$ and $\mathrm{HB}$ there is a decrease in the binding distance. It is also evident that all $\mathrm{Y}-\mathrm{A}$ bonds are systematically lengthened upon complexation (see values in parentheses). These results reveal that the $\mathrm{N} \cdots \mathrm{Y}$ interaction weakens the $\mathrm{Y}-\mathrm{A}$ bonds. Except for the boron complexes all the other complexes present a planar structure. The equilibrium angle, $\mathrm{C}-\mathrm{N} \cdots \mathrm{Y}$, is close to $180^{\circ}$ in all complexes except for the ${ }^{3} \mathrm{CH}_{2} \mathrm{CHN} \cdots \mathrm{BeH}_{2},{ }^{3} \mathrm{CH}_{2} \mathrm{CHN} \cdots \mathrm{BeF}_{2}$, and ${ }^{3} \mathrm{CH}_{2} \mathrm{CHN} \cdots \mathrm{BH}_{3}$ complexes where the equilibrium angle $\mathrm{C}-\mathrm{N} \cdots \mathrm{Y}$ is close to $150^{\circ}$.

\section{Interaction energies}

The interaction energy provides a measure of the strength of the interaction between $\mathrm{N}$ and $\mathrm{Y}(\mathrm{Y}=\mathrm{Li}, \mathrm{Be}, \mathrm{B}, \mathrm{Cl}, \mathrm{H})$. Table 1 presents the interaction energies for the complexes calculated at the HF, MP2, and CCSD(T) levels of theory. It can be seen from Table 1 that the $\operatorname{CCSD}(\mathrm{T})$ method predicts a significant range of strength: from -0.98 (in $\mathrm{CH}_{2}=\mathrm{CHN} \cdots \mathrm{ClH}$ complex) to $-39.03 \mathrm{kcal} / \mathrm{mol}$ (in $\mathrm{CH}_{2}=$ $\mathrm{CHN} \cdots \mathrm{BH}_{3}$ complex) indicating that these interactions are comparable in strength to the well-documented hydrogen bonding interactions [37]. 
Fig. 1 Optimized geometries of the complexes between ${ }^{3} \mathrm{CH}_{2} \mathrm{CHN}$ and the Lewis acids YA ( $\mathrm{LiH}, \mathrm{LiF}, \mathrm{BeH}_{2}, \mathrm{BeF}_{2}$, $\left.\mathrm{BH}_{3}, \mathrm{BF}_{3}, \mathrm{ClH}, \mathrm{ClF}, \mathrm{HCl}, \mathrm{HF}\right)$. In addition, the variation of the $\mathrm{Y}-\mathrm{A}$ bond length (defined as the difference between the bond length in the complex and isolated molecule) upon complex formation is indicated in parentheses. Bond lengths are in $\AA$ and bond angles in degrees

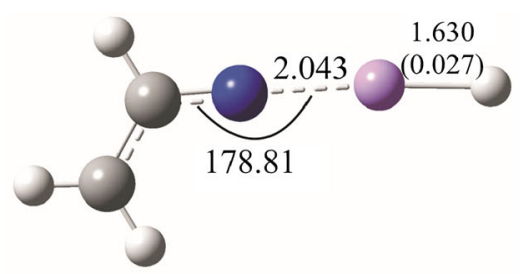

$\mathrm{CH}_{2} \mathrm{CHN} \cdots \mathrm{LiH}$
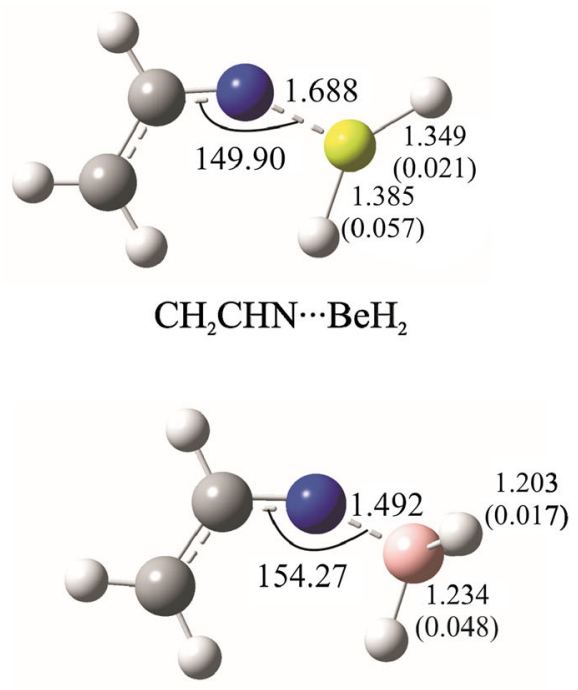

$\mathrm{CH}_{2} \mathrm{CHN} \cdots \mathrm{BH}_{3}$

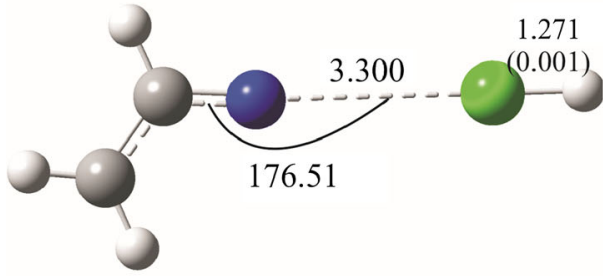

$\mathrm{CH}_{2} \mathrm{CHN} \cdots \mathrm{ClH}$

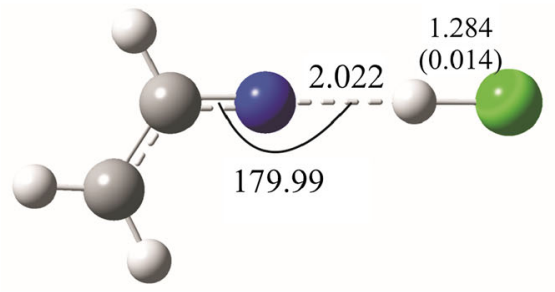

$\mathrm{CH}_{2} \mathrm{CHN} \cdots \mathrm{HCl}$

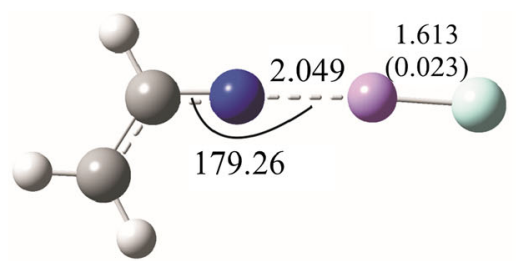

$\mathrm{CH}_{2} \mathrm{CHN} \cdots \mathrm{LiF}$
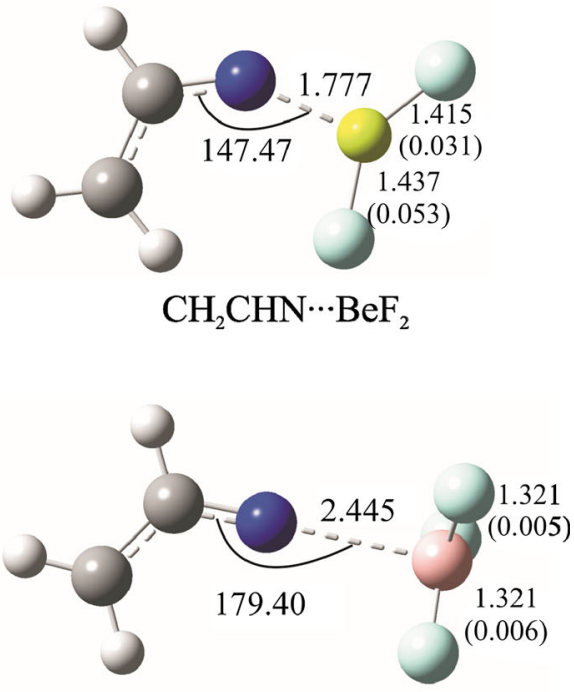

$\mathrm{CH}_{2} \mathrm{CHN} \cdots \mathrm{BF}_{3}$
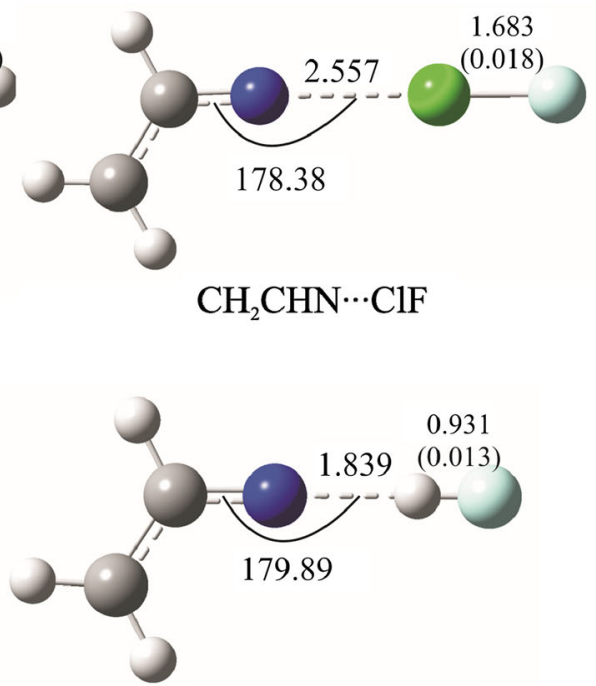

$\mathrm{CH}_{2} \mathrm{CHN} \cdots \mathrm{HF}$
In the LiBs, the interaction energies at the HF, MP2, and CCSD(T) levels are practically identical, which means that the electronic correlation has not effect on the strength of the interactions $\mathrm{N} \cdots \mathrm{Li}$, in the rest of the complexes the electronic correlation significantly affects the interaction energy.
It is known that the higher the electron-withdrawing capacity of A (group bonded to Y, hydrogen and halogen, respectively) the stronger is the interaction [9].

In the ${ }^{3} \mathrm{CH}_{2} \mathrm{CHN} \cdots \mathrm{Li}-\mathrm{A}$ and ${ }^{3} \mathrm{CH}_{2} \mathrm{CHN} \cdots \mathrm{Be}-\mathrm{A}$ (with $\mathrm{A}=\mathrm{H}, \mathrm{F})$ complexes, the electron-withdrawing fluorine atom has practically no effect on the strength of the $\mathrm{N} \cdots \mathrm{Li}$ 
Table 1 Interaction energies calculated using the HF, MP2, and $\mathrm{CCSD}(\mathrm{T})$ methods $(\mathrm{kcal} / \mathrm{mol})$

\begin{tabular}{lrrr}
\hline Complexes & \multicolumn{1}{c}{$\Delta E^{\mathrm{HF}}$} & $\Delta E^{\mathrm{MP} 2}$ & $\Delta E^{\mathrm{CCSD}(\mathrm{T})}$ \\
\hline $\mathrm{CH}_{2}=\mathrm{CHN} \cdots \mathrm{LiH}$ & -15.33 & -15.99 & -15.99 \\
$\mathrm{CH}_{2}=\mathrm{CHN} \cdots \mathrm{LiF}$ & -15.00 & -15.91 & -15.69 \\
$\mathrm{CH}_{2}=\mathrm{CHN} \cdots \mathrm{BeH}_{2}$ & -7.60 & -15.54 & -25.37 \\
$\mathrm{CH}_{2}=\mathrm{CHN} \cdots \mathrm{BeF}_{2}$ & -12.53 & -15.69 & -26.59 \\
$\mathrm{CH}_{2}=\mathrm{CHN} \cdots \mathrm{BH}_{3}$ & -4.79 & -22.41 & -39.03 \\
$\mathrm{CH}_{2}=\mathrm{CHN} \cdots \mathrm{BF}_{3}$ & -2.86 & -4.41 & -6.22 \\
$\mathrm{CH}_{2}=\mathrm{CHN} \cdots \mathrm{ClH}$ & 0.31 & -0.40 & -0.98 \\
$\mathrm{CH}_{2}=\mathrm{CHN} \cdots \mathrm{ClF}$ & -1.62 & -4.76 & -4.69 \\
$\mathrm{CH}_{2}=\mathrm{CHN} \cdots \mathrm{HCl}$ & -2.42 & -4.52 & -4.61 \\
$\mathrm{CH}_{2}=\mathrm{CHN} \cdots \mathrm{HF}$ & -5.45 & -7.10 & -7.53 \\
\hline
\end{tabular}

All calculated interaction energies are BSSE corrected

and $\mathrm{N} \cdots \mathrm{Be}$ interactions (the interaction energies are approximately equal).

In the case of the $\mathrm{BBs}$, the interaction energy is more negative for ${ }^{3} \mathrm{CH}_{2} \mathrm{CHN} \cdots \mathrm{BH}_{3}$ than for ${ }^{3} \mathrm{CH}_{2} \mathrm{CHN} \cdots \mathrm{BF}_{3}$ complexes, despite the strong electron-withdrawing effect of the fluorine atom; thus some additional factor is involved. A similar situation occurs when analyzing the relative Lewis acidity of boron trihalides [16]. The Lewis acidity of these acids increases in the order $\mathrm{BF}_{3}<\mathrm{BC}_{3}<\mathrm{BBr}_{3}$. According to Politzer and co-workers [16], this fact can be better understood and explained with the concept of "charge capacities". According to these authors, the relative Lewis acidity of these molecules is due to the ability to accept charge density. This magnitude is increased in the order $\mathrm{BF}_{3}<\mathrm{BCl}_{3}<\mathrm{BBr}_{3}$. It is logical to think that the major relative Lewis acidity of the $\mathrm{BH}_{3}$ molecule is due to its higher "charge capacities" in relation to the $\mathrm{BF}_{3}$ molecule.

In $\mathrm{XBs}$ and $\mathrm{HBs}$, the stronger $\mathrm{N} \cdots \mathrm{Y}$ (with $\mathrm{Y}=\mathrm{Cl}, \mathrm{H}$ ) interactions occur when $\mathrm{Y}$ is bonded to fluorine.

\section{Vibrational analysis}

The formation of a complex also has a strong effect on the frequencies of the vibrational normal modes of the Lewis acid. Table 2 presents selected vibrational modes of the Lewis acids and the complexed species.

A characteristic of conventional HBs, also called proper HBs, $\mathrm{B} \cdots \mathrm{H}-\mathrm{A}$, is that its formation leads to a weakening of the $\mathrm{H}-\mathrm{A}$ bond [38]. This weakening is accompanied by a bond elongation and a concomitant decrease of the $\mathrm{H}-\mathrm{A}$ stretch vibration frequency (shifted to the red), compared with the isolated $\mathrm{H}-\mathrm{A}$ molecule. In contrast, in the formation of the so-called improper HBs, the $\mathrm{H}-\mathrm{A}$ bond shortens, and its vibrational frequency increases (shift to the blue). In addition, it has been reported that the formation of XBs can also lead to a lengthening (red shift) or shortening (blue shift) of the $\mathrm{X}-\mathrm{Y}$ bond (with $\mathrm{X}, \mathrm{Y}=\mathrm{F}, \mathrm{Cl}, \mathrm{Br}$ ) [39]. For this
Table 2 Selected computed frequencies $\left(\mathrm{cm}^{-1}\right)$ at MP2/6$311++\mathrm{G}(2 \mathrm{~d}, 2 \mathrm{p})$ level of theory

\begin{tabular}{|c|c|c|c|c|}
\hline Complex & $\begin{array}{l}\text { Vibrational } \\
\text { mode }\end{array}$ & $v_{\text {Mon }}^{\mathrm{a}}$ & $v_{\mathrm{Dim}}^{\mathrm{b}}$ & $\Delta v^{\mathrm{c}}$ \\
\hline $\mathrm{CH}_{2}=\mathrm{CHN} \cdots \mathrm{LiH}$ & $v(\mathrm{LiH})$ & 1419.46 & 1349.33 & -70.13 \\
\hline $\mathrm{CH}_{2}=\mathrm{CHN} \cdots \mathrm{LiF}$ & $v(\mathrm{LiF})$ & 889.38 & 878.46 & -10.92 \\
\hline \multirow[t]{3}{*}{$\mathrm{CH}_{2}=\mathrm{CHN} \cdots \mathrm{BeH}_{2}$} & $\delta_{\mathrm{s}}\left(\mathrm{BeH}_{2}\right)$ & 741.95 & 838.23 & 96.28 \\
\hline & $v_{\mathrm{s}}(\mathrm{BeH})$ & $-{ }^{\mathrm{d}}$ & 1864.26 & \\
\hline & $v_{\mathrm{a}}(\mathrm{BeH})$ & 2286.48 & 2073.18 & -213.30 \\
\hline \multirow[t]{3}{*}{$\mathrm{CH}_{2}=\mathrm{CHN} \cdots \mathrm{BeF}_{2}$} & $\delta_{\mathrm{s}}\left(\mathrm{BeF}_{2}\right)$ & 363.37 & 450.85 & 87.48 \\
\hline & $v_{\mathrm{s}}(\mathrm{BeF})$ & $-{ }^{\mathrm{d}}$ & 811.69 & \\
\hline & $v_{\mathrm{a}}(\mathrm{BeF})$ & 1571.54 & 1327.49 & -244.05 \\
\hline \multirow[t]{3}{*}{$\mathrm{CH}_{2}=\mathrm{CHN} \cdots \mathrm{BH}_{3}$} & $\delta_{\mathrm{s}}\left(\mathrm{BH}_{3}\right)$ & 1171.54 & 1096.59 & -74.95 \\
\hline & $v_{\mathrm{s}}(\mathrm{BH})$ & $-{ }^{\mathrm{d}}$ & 2508.12 & \\
\hline & $v_{\mathrm{a}}(\mathrm{BH})$ & 2738.06 & 2556.22 & -181.84 \\
\hline \multirow[t]{3}{*}{$\mathrm{CH}_{2}=\mathrm{CHN} \cdots \mathrm{BF}_{3}$} & $\delta_{\mathrm{s}}\left(\mathrm{BF}_{3}\right)$ & 693.28 & 615.69 & -77.59 \\
\hline & $v_{\mathrm{s}}(\mathrm{BF})$ & $-{ }^{\mathrm{d}}$ & 868.21 & \\
\hline & $v_{\mathrm{a}}(\mathrm{BF})$ & 1449.36 & 1423.74 & -25.62 \\
\hline $\mathrm{CH}_{2}=\mathrm{CHN} \cdots \mathrm{ClH}$ & $v(\mathrm{ClH})$ & 3003.93 & 2996.4 & -7.53 \\
\hline $\mathrm{CH}_{2}=\mathrm{CHN} \cdots \mathrm{ClF}$ & $v(\mathrm{ClF})$ & 752.15 & 749.81 & -2.34 \\
\hline $\mathrm{CH}_{2}=\mathrm{CHN} \cdots \mathrm{HCl}$ & $v(\mathrm{HCl})$ & 3003.93 & 2820.77 & -183.16 \\
\hline $\mathrm{CH}_{2}=\mathrm{CHN} \cdots \mathrm{HF}$ & $v(\mathrm{HF})$ & 4168.97 & 3870.77 & -298.20 \\
\hline
\end{tabular}

${ }^{a} v_{\text {Mon }}$ represents the monomer (Lewis acid) vibrational frequency

b $v_{\text {Dim }}$ represents the dimer vibrational frequency

c $\Delta v$ represents the frequency shift, defined as the difference between the frequency of the certain vibrational mode in the complex and in the Lewis acid YA

d $v_{\mathrm{s}}(\mathrm{BeA})$ and $v_{\mathrm{s}}(\mathrm{BA})$ are not listed because these symmetric stretches are IR inactive

reason, the effects of the formation of the complexes on the $\mathrm{Y}-\mathrm{A}$ bond were also explored in this work.

The variation in the $\mathrm{Y}-\mathrm{A}$ bond distance upon complexation, $\Delta d(\mathrm{Y}-\mathrm{A})$, that is, the difference between the distance $d(\mathrm{Y}-\mathrm{A})$ in the complexes and in the isolated monomers (YA), is presented in Fig. 1 and the IR spectrum and the predicted shifts with respect to the free monomers at MP2/6-311++G(2d,2p) level are presented in Table 2 . All $\Delta d(\mathrm{Y}-\mathrm{A})$ values are positive; that is, the $\mathrm{Y}-\mathrm{A}$ bond is stretched as result of the complexation. The elongation of the $\mathrm{Y}-\mathrm{A}$ bond is accompanied by a decrease in the strength of the $\mathrm{Y}-\mathrm{A}$ bond. This idea is supported by the analysis of the vibrational frequencies (see Table 2). In all cases, it is observed a decrease of the frequency of the vibration associated with the stretching of the Y-A bond, compared with the isolated molecule. Therefore, the interactions studied here, we can consider as conventionals.

In the LiBs, $\mathrm{XBs}$, and HBs studied here, there is a single $\mathrm{Y}-\mathrm{A}$ (with $\mathrm{Y}=\mathrm{Li}, \mathrm{Cl}, \mathrm{H}$ and $\mathrm{A}=\mathrm{H}, \mathrm{F}$ ) stretching mode [v(YA)] that is in every case shifted to the red in comparison with the isolated molecule. That is, the formation of the complex weakens the $\mathrm{Y}-\mathrm{A}$ bond. 
Table 3 Local topological properties of the electronic charge density distribution calculated at the position of the NY..BCPs

\begin{tabular}{llllr}
\hline Complexes & $\rho\left(\mathbf{r}_{\mathrm{b}}\right)$ & $\nabla^{2} \rho\left(\mathbf{r}_{\mathrm{b}}\right)$ & $\left|\lambda_{1}\right| / \lambda_{3}$ & \multicolumn{1}{c}{$H\left(\mathbf{r}_{\mathrm{b}}\right)$} \\
\hline $\mathrm{CH}_{2}=\mathrm{CHN} \cdots \mathrm{LiH}$ & 0.0234 & 0.1593 & 0.1689 & 0.0071 \\
$\mathrm{CH}_{2}=\mathrm{CHN} \cdots \mathrm{LiF}$ & 0.0231 & 0.1566 & 0.1672 & 0.0071 \\
$\mathrm{CH}_{2}=\mathrm{CHN} \cdots \mathrm{BeH}_{2}$ & 0.0655 & 0.4433 & 0.2186 & -0.0047 \\
$\mathrm{CH}_{2}=\mathrm{CHN} \cdots \mathrm{BeF}_{2}$ & 0.0519 & 0.3316 & 0.2056 & -0.0021 \\
$\mathrm{CH}_{2}=\mathrm{CHN} \cdots \mathrm{BH}_{3}$ & 0.1411 & 0.6823 & 0.2227 & -0.1047 \\
$\mathrm{CH}_{2}=\mathrm{CHN} \cdots \mathrm{BF}_{3}$ & 0.0190 & 0.0553 & 0.1168 & 0.0004 \\
$\mathrm{CH}_{2}=\mathrm{CHN} \cdots \mathrm{ClH}$ & 0.0057 & 0.0228 & 0.1191 & 0.0012 \\
$\mathrm{CH}_{2}=\mathrm{CHN} \cdots \mathrm{ClF}$ & 0.0252 & 0.1028 & 0.1369 & 0.0027 \\
$\mathrm{CH}_{2}=\mathrm{CHN} \cdots \mathrm{HCl}$ & 0.0223 & 0.0717 & 0.2167 & 0.0013 \\
$\mathrm{CH}_{2}=\mathrm{CHN} \cdots \mathrm{HF}$ & 0.0311 & 0.0944 & 0.2467 & 0.0009 \\
\hline
\end{tabular}

$\rho\left(\mathbf{r}_{\mathrm{b}}\right)$ : electron density; $\nabla^{2} \rho\left(\mathbf{r}_{\mathrm{b}}\right)$ : Laplacian of the electron density; $\left|\lambda_{1}\right| / \lambda_{3}$ : ratio of the perpendicular contractions of $\rho\left(\mathbf{r}_{\mathrm{b}}\right)$ to its parallel expansion at the N... $\mathrm{Y}$ BCP; $H\left(\mathbf{r}_{\mathrm{b}}\right)$ : electronic energy density. The values of all properties are in atomic units

In the $\mathrm{BeB}$, the $\mathrm{Be}-\mathrm{A}$ stretching modes appear as symmetric $\left[v_{\mathrm{s}}(\mathrm{BeA})\right]$ and asymmetric $\left[v_{\mathrm{a}}(\mathrm{BeA})\right]$ combinations. In $\mathrm{CH}_{2} \mathrm{CHN} \cdots \mathrm{BeA}_{2}$ complexes, the asymmetric stretching appears significantly shifted to the red. These results agree with those reported by Yáñez et al. [13] for similar systems ( $\mathrm{B} \cdots \mathrm{BeCl}_{2}$, with $\mathrm{B}$ : Lewis base). In addition, the symmetric deformation mode of the $\mathrm{BeA}_{2}$ subunits $\left[\delta_{\mathrm{s}}\left(\mathrm{BeA}_{2}\right)\right]$ is significantly blue-shifted in both complexes. This is so because in the complexes the $\mathrm{BeA}_{2}$ subunits are bent, and therefore the symmetric deformations $\left[\delta_{\mathrm{s}}\left(\mathrm{BeA}_{2}\right)\right]$ are unavoidably coupled with the stretching of the $\mathrm{N} \cdots \mathrm{Be}$ interactions. In other words, the symmetric deformations lead to a compression of the $\mathrm{N} \cdots \mathrm{Be}$ interaction and vice versa.

In the $\mathrm{BB}$, both subunits $\mathrm{BA}_{3}$ (with $\mathrm{A}=-\mathrm{H},-\mathrm{F}$ ) have two $\mathrm{B}-\mathrm{A}$ stretching modes, the $\mathrm{B}-\mathrm{A}$ symmetric stretch $\left[v_{\mathrm{s}}(\mathrm{BA})\right]$ and the $\mathrm{B}-\mathrm{A}$ asymmetric stretch $\left[v_{\mathrm{a}}(\mathrm{BA})\right]$. In addition, the symmetric deformation or "umbrella" mode $\left[\delta_{\mathrm{s}}\left(\mathrm{BA}_{3}\right)\right]$ is also observed. From the data in Table 2, it can be seen that $v_{\mathrm{a}}(\mathrm{BA})$ and $\delta_{\mathrm{s}}\left(\mathrm{BA}_{3}\right)$ vibrational modes are found shifted toward the red. These results reveal that the $\mathrm{N} \cdots \mathrm{B}$ interaction weakens the $\mathrm{B}-\mathrm{A}$ bonds.

Understanding of the nature of these intermolecular interactions requires a deep analysis. For this purpose, we describe in the following sub-section a topological analysis of the electron charge density and its Laplacian function within the framework of the quantum theory of atoms in molecules, QTAIM.

\section{QTAIM analysis}

The topological analysis of the electron density, $\rho(\mathbf{r})$, and its Laplacian function, $\nabla^{2} \rho(\mathbf{r})$, was performed to understand the origin of the interactions studied here, and the results are summarized in Table 3 and Fig. 2. According to the AIM

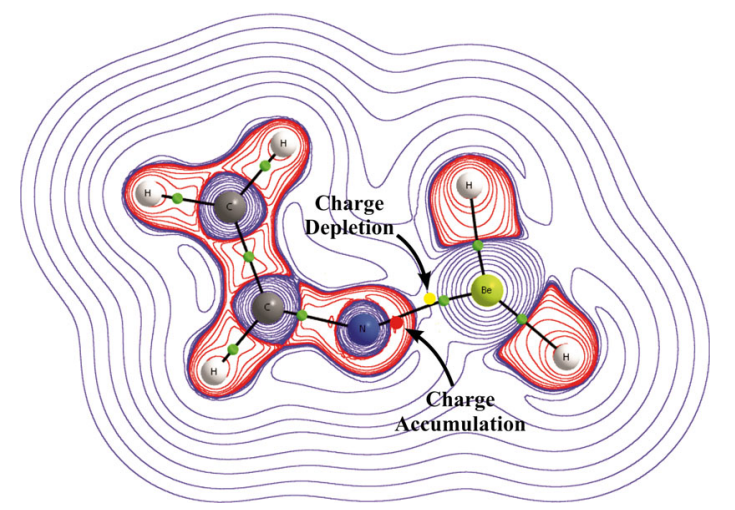

Fig. 2 Contour map of $L(\mathbf{r})=-1 / 4 \nabla^{2} \rho(\mathbf{r})$ function for ${ }^{3} \mathrm{CH}_{2} \mathrm{CHN} \cdots \mathrm{BeH}_{2}$ complex. Blue lines denote $L(\mathbf{r})<0$ and red lines $L(\mathbf{r})>0$. In addition, the CP $(3,-3)$ of the nitrogen atom (red dot) and the $\mathrm{CP}(3,+1)$ (yellow dot) of the $L(\mathbf{r})$ function are shown. The black lines indicate the bond paths and the green dots indicate the BCP of the $\rho(\mathbf{r})$ topology. Note the anisotropic distribution of the charge concentration in the VSCC of the $\mathrm{N}$ atom (Color figure online)

theory, the presence of a bond path, BP, is a universal indicator of the existence of a chemical bond [40]. In all complexes, a $\mathrm{BP}$ is formed between the $\mathrm{N}$ and $\mathrm{Y}$ (with $\mathrm{Y}=\mathrm{Li}$, $\mathrm{Be}, \mathrm{B}, \mathrm{Cl}, \mathrm{H}$ ) atoms (molecular graphs shown in Fig. S1 of Supplementary Material). In addition, in the $\mathrm{CH}_{2} \mathrm{CHN} \cdots \mathrm{BeF}_{2}$ complex, it can also be observed a line of maximum electronic charge density between $\mathrm{F}$ and $\mathrm{H}$ atoms. That is, a hydrogen bond $\mathrm{C}-\mathrm{H} \cdots \mathrm{F}$ is formed. However, properties at the bond critical point (BCP) $\mathrm{H} \cdots \mathrm{F}$ and at the ring critical point (RCP) $\left[\rho\left(\mathbf{r}_{\mathrm{b}}\right)=0.0083 \mathrm{au}, \varepsilon_{\mathrm{RCP}}=0.37\right]$ and the distance between the BCP and the RCP of only $0.41 \AA$, reflect structural instability; that is, the bond can be easily broken [41].

Properties at the BCP of a BP allow to classify the interaction between two atoms as a shared-shell (covalent) or a closed-shell (ionic or van der Waals interaction) interaction [42]. In all N ‥ Y intermolecular interactions, the BCP (see data in Table 3) presents properties typical of closed-shell interactions: $\rho\left(\mathbf{r}_{\mathrm{b}}\right)$ relatively low, $\nabla^{2} \rho\left(\mathbf{r}_{\mathrm{b}}\right)>0$ and $\left|\lambda_{1}\right| /$ $\lambda_{3}<1$.

The $L(\mathbf{r})=-1 / 4 \nabla^{2} \rho(\mathbf{r})$ function is more sensitive and provides complementary information from the molecular electronic system under observation. This function shows the regions of the space where $\rho(\mathbf{r})$ is locally concentrated $[L(\mathbf{r})>0]$ or depleted $[L(\mathbf{r})<0][35,36]$. In previous works, we have used this function to characterize XBs [35, 36] and we have determined that triplet vinyl nitrene has lone pairs available to interact electrostatically with a Lewis acid to form a Lewis adduct [26]. Figure 2 shows the contour map of the $L(\mathbf{r})$ function and molecular graph for the ${ }^{3} \mathrm{CH}_{2} \mathrm{CHN} \cdots \mathrm{BeH}_{2}$ complex. In this figure, it can clearly be observed a lump-hole interaction. That is to say, the $\mathrm{N} \cdots \mathrm{Be}$ interaction is the result of the combination of a local charge concentration [lump - CP $(3,-3)$ in $L(\mathbf{r})]$ in the valence shell charge concentration (VSCC) of the nitrogen 
atom with a local charge depletion [hole - CP $(3,+1)$ in $L(\mathbf{r})]$ in the VSCC of the beryllium atom. Popelier called this statement "the Laplacian complementary principle" [43]. In every complex, it can be observed a similar situation. Therefore, the topological analysis of the $L(\mathbf{r})$ function reveals that the formation of the studied complexes is electrostatic in nature. These interactions are established between the charge density provided by the lone pair of the nitrogen atom and the charge density depletion region of the $\mathrm{Y}$ atom. In addition, the localization of the thinning of the electron density in the VSCC of the Y atom determines the geometry of these complexes.

\section{Conclusions}

The present study has afforded the first theoretical evidence of the formation of complexes between triplet vinyl nitrene $\left({ }^{3} \mathrm{CH}_{2} \mathrm{CHN}\right)$ and some Lewis acids YA ( $\mathrm{LiH}, \mathrm{LiF}, \mathrm{BeH}_{2}$, $\left.\mathrm{BeF}_{2}, \mathrm{BH}_{3}, \mathrm{BF}_{3}, \mathrm{ClH}, \mathrm{ClF}, \mathrm{HCl}, \mathrm{HF}\right)$. Quantum chemical calculations predict that the molecular complexes ${ }^{3} \mathrm{CH}_{2} \mathrm{CHN} \cdots \mathrm{Y}-\mathrm{A}$ are always more stable than the separated ${ }^{3} \mathrm{CH}_{2} \mathrm{CHN}$ and $\mathrm{Y}-\mathrm{A}$ species. Accordingly, some of these complexes may serve to detect and characterize experimentally the elusive triplet vinyl nitrene. In addition, in most cases (except in ${ }^{3} \mathrm{CH}_{2} \mathrm{CHN} \cdots \mathrm{BH}_{3}$ and ${ }^{3} \mathrm{CH}_{2} \mathrm{CHN} \cdots \mathrm{BF}_{3}$ complexes) a planar structure is observed between the ${ }^{3} \mathrm{CH}_{2} \mathrm{CHN}$ subunit and the Lewis acids. Complex formation results in the decrease in the strength of the $\mathrm{Y}-\mathrm{A}$ bond as observed by the elongation of the $\mathrm{Y}-\mathrm{A}$ bond and the decrease of the frequency of the vibration (shift to red) associated with the stretching of the $\mathrm{Y}-\mathrm{A}$ bond, compared with the isolated molecule. According to QTAIM, the formation of the studied complexes results from the atomic interaction between the $\mathrm{N}$ and $\mathrm{Y}$ atoms. Additionally, the $L(\mathbf{r})$ function reveals that the stability of the complexes is mainly of character electrostatic and is established between the lone pair of the nitrogen atom and the charge density depletion region of the $\mathrm{Y}$ atom. Moreover, the localization of the depletion charge density in the VSCC of Y atom determines the geometry of the complexes.

Acknowledgments D. J. R. Duarte gratefully acknowledges a Grant from the EuroTANGO II Erasmus Mundus Program that made possible his stay at Porto. D. J. R. Duarte also acknowledges the Universidad Nacional del Nordeste (UNNE). M. S. Miranda thanks Fundação para a Ciência e a Tecnologia, FCT, Lisbon, Portugal, for the financial support under the frame of Ciência 2008 program.

\section{References}

1. Hunter CA (1994) Meldola Lecture. The role of aromatic interactions in molecular recognition. Chem Soc Rev 23:101-109
2. Philp D, Stoddart JF (1996) Self-assembly in natural and unnatural systems. Angew Chem Int Ed Engl 35:1154-1196

3. Rudkevich DM (2004) Emerging supramolecular chemistry of gases. Angew Chem Int Ed 43:558-571

4. Llanes-Pallas A, Palma C-A, Piot C, Belbakra A, Listorti A, Prato M, Samori P, Armaroli N, Bonifazi D (2009) Engineering of supramolecular H-bonded nanopolygons via self-assembly of programmed molecular modules. J Am Chem Soc 131:509-520

5. Grabowski SJ (2013) Non-covalent interactions - QTAIM and NBO analysis. J Mol Model 19:4713-4721

6. Jeffrey GA, Saenger W (1991) Hydrogen bonding in biological structures. Springer, Berlin

7. Jeffrey GA (1997) An introduction to hydrogen bonding. Oxford University Press, New York

8. Desiraju GR, Steiner T (1999) The weak hydrogen bond in structural chemistry and biology. Oxford University Press, New York

9. Politzer P, Murray JS (2013) Halogen bonding: an interim discussion. Chem Phys Chem 14:278-294

10. Legon AC (2010) The halogen bond: an interim perspective. Phys Chem Chem Phys 12:7736-7747

11. Li Q-Z, Li R, Guo P, Li H, Li W-Z, Cheng J-B (2012) Competition of chalcogen bond, halogen bond, and hydrogen bond in SCS-HOX and SeCSe-HOX $(\mathrm{X}=\mathrm{Cl}$ and $\mathrm{Br})$ complexes. Comput Theor Chem 980:56-61

12. Wang W, Ji B, Zhang Y (2009) Chalcogen bond: a sister noncovalent bond to halogen bond. J Phys Chem A 113:8132-8135

13. Yáñez M, Sanz P, Mó M, Alkorta I, Elguero J (2009) Beryllium bonds, do they exist? J Chem Theory Comput 5:2763-2771

14. Eskandari K (2012) Characteristics of beryllium bonds; a QTAIM study. J Mol Model 18:3481-3487

15. Esrafili MD (2012) Characteristics and nature of the intermolecular interactions in boron-bonded complexes with carbene as electron donor: an ab initio, SAPT and QTAIM study. J Mol Model 18:2003-2011

16. Brinck T, Murray JS, Politzer P (1993) A computational analysis of the bonding in boron trifluoride and boron trichloride and their complexes with ammonia. Inorg Chem 32:2622-2625

17. Del Bene JE, Alkorta I, Elguero J (2009) Characterizing complexes with $\mathrm{F}-\mathrm{Li}^{+}-\mathrm{F}$ lithium bonds: structures, binding energies, and spin-spin coupling constants. J Phys Chem A 113:8359-8365

18. Tong J, Li Y, Wu D, Li Z-R, Huang X-R (2010) Lithium bonding interaction hyperpolarizabilities of various Li-bond dimers. J Phys Chem A 114:5888-5893

19. Murray JS, Riley KE, Politzer P, Clark T (2010) Directional weak intermolecular interactions: sigma-hole bonding. Aust J Chem 63:1598-1607

20. Clark T, Hennemann M, Murray JS, Politzer P (2007) Halogen bonding: the $\sigma$-hole. J Mol Model 13:291-296

21. Scriven EFV (ed) (1984) Azides and nitrene-reactivity and utility. Academic Press, New York

22. Lwowski W (ed) (1970) Nitrenes. Wiley, New York

23. Patai S (ed) (1971) The chemistry of the azido group. Wiley, New York

24. Gritsan NP, Platz MS, Borden WT, Kutateladze AG (eds) (2005) Computational methods in photochemistry. Taylor \& Francis, Boca Raton

25. Moss RA, Platz MS, Jones M (eds) (2004) Reactive intermediate chemistry. Wiley-Interscience, Hoboken

26. Duarte DRJ, Miranda MS, da Silva EJC (2014) Computational study on the vinyl azide decomposition. J Phys Chem A 118:5038-5045

27. Romano RM, Picone AL, Downs AJ (2006) Matrix-isolated van der Waals complexes formed between CS2 and dihalogen molecules $\mathrm{XY}$, where $\mathrm{XY}=\mathrm{Cl} 2, \mathrm{Br} 2, \mathrm{BrCl}, \mathrm{ICl}$, or $\mathrm{IBr}$. J Phys Chem A 110:12129-12135 
28. Picone AL, Romano RM (2010) Infrared matrix-isolation studies of the CS2 $\cdots \mathrm{HCl}$ molecular complex. J Mol Struct 978:187-190

29. Buchberger AR, Danforth SJ, Bloomgren KM, Rohde JA, Smith EL, Gardener CCA, Phillips JA (2013) Condensed-phase effects on the structural properties of $\mathrm{FCH}_{2} \mathrm{CN} \cdots \mathrm{BF}_{3}$ and $\mathrm{ClCH}_{2}$ $\mathrm{CN} \cdots \mathrm{BF}_{3}$ : a matrix-isolation and computational study. J Phys Chem B 117:11687-11696

30. Møller C, Plesset MS (1934) Note on an approximation treatment for many-electron systems. Phys Rev 46:618-622

31. Raghavachari K, Trucks GW, Pople JA, Head-Gordon M (1989) A fifth-order perturbation comparison of electron correlation theories. Chem Phys Lett 157:479-483

32. Boys SF, Bernardi F (1970) The calculation of small molecular interactions by the differences of separate total energies. Some procedures with reduced errors. Mol Phys 19:553-566

33. AIMAll (Version 11.12.19), Todd A. Keith, TK (2011) Gristmill Software, Overland Park KS, USA, (aim.tkgristmill.com)

34. Frisch MJ, Trucks GW, Schlegel HB, Scuseria GE, Robb MA, Cheeseman JR, Montgomery Jr. JA, Vreven T, Kudin KN, Burant JC, Millam JM, Iyengar SS, Tomasi J, Barone V, Mennucci B, Cossi M, Scalmani G, Rega N, Petersson GA, Nakatsuji H, Hada M, Ehara M, Toyota K, Fukuda R, Hasegawa J, Ishida M, Nakajima T, Honda Y, Kitao O, Nakai H, Klene M, Li X, Knox JE, Hratchian HP, Cross JB, Bakken V, Adamo C, Jaramillo J, Gomperts R, Stratmann RE, Yazyev O, Austin AJ, Cammi R, Pomelli C, Ochterski JW, Ayala PY, Morokuma K, Voth GA, Salvador P, Dannenberg JJ, Zakrzewski VG, Dapprich S, Daniels $\mathrm{AD}$, Strain MC, Farkas O, Malick DK, Rabuck AD, Raghavachari K, Foresman JB, Ortiz JV, Cui Q, Baboul AG, Clifford S, Cioslowski J, Stefanov BB, Liu G, Liashenko A, Piskorz P,
Komaromi I, Martin RL, Fox DJ, Keith T, Al-Laham MA, Peng CY, Nanayakkara A, Challacombe M, Gill PMW, Johnson B, Chen W, Wong MW, Gonzalez C, Pople JA, (2004) Gaussian 03, Revision C.02. Gaussian, Inc, Wallingford CT

35. Duarte DJR, Sosa GL, Peruchena NM (2013) Nature of halogen bonding. A study based on the topological analysis of the Laplacian of the electron charge density and an energy decomposition analysis. J Mol Model 19:2035-2041

36. Duarte DJR, Angelina EL, Peruchena NM (2012) On the strength of the halogen bonds: mutual penetration, atomic quadrupole moment and Laplacian distribution of the charge density analyses. Comput Theor Chem 998:164-172

37. Alkorta I, Blanco F, Solimannejad M, Elguero J (2008) Competition of hydrogen bonds and halogen bonds in complexes of hypohalous acids with nitrogenated bases. J Phys Chem A 112:10856-10863

38. Alkorta I, Elguero J (1998) Non-conventional hydrogen bonds. Chem Soc Rev 27:163-170 (and references cited therein)

39. Wang W, Wong N-B, Zheng W, Tiang A (2004) Theoretical study on the blue shifting halogen bond. J Phys Chem A 108:1799-1805

40. Bader RFW (1998) A bond path: a universal indicator of bonded interactions. J Phys Chem A 102:7314-7323

41. Cremer D, Kraka E, Slee TS, Bader RFW, Lau CDH, Nguyen-Dang TT, MacDougall PJ (1983) Description of homoaromaticity in terms of electron distributions. J Am Chem Soc 105:5069-5075

42. Bader RFW, Essén H (1984) The characterization of atomic interactions. J Chem Phys 80:1943-1960

43. Popelier P (ed) (2000) Atoms in molecules: an introduction. Prentice-Hall, Harlow 